\title{
Emergent publics of alcohol and other drug policymaking
}

\begin{abstract}
Alcohol and other drug (AOD) policy is developed within complex networks of social, economic and political forces. One of the key ideas informing this development is that of the 'public' of AOD problems and policy solutions. To date, however, little scholarly attention has been paid to notions of the public in AOD policymaking. Precisely how are publics articulated by those tasked with policy development and implementation? In this article we explore this question in detail. We analyze 60 qualitative interviews with Australian and Canadian AOD policymakers and service providers, arguing that publics figure in these interviews as pre-existing groups that must be managed - contained or educated - to allow policy to proceed. Drawing on Michael Warner's work, we argue that publics should be understood instead as made in policy processes rather than as preceding them, and we conclude by reframing publics as emergent collectivities of interest. In closing, we briefly scrutinize the widely accepted model of good policy development, that of 'consultation', arguing that, if publics are to be understood as emergent, and therefore policy's opportunities as more open than is often suggested, a different figure - here that of 'conference' is tentatively suggested - may be required.
\end{abstract}

\section{Keywords}

Policy, drugs, Michael Warner, Australia, Canada, Interviews 
In August 2015, following a series of negative media stories and facing weak polling results, then Prime Minister of Australia Tony Abbott launched an anti-drug initiative entitled 'Dob in a drug dealer' (OPMA, 2015). Linked to current interest in what has been dubbed, despite the public protestations of researchers, Australia's 'ice [crystalline methamphetamine] epidemic' (Fitzgerald, 2015), the initiative was backed with a commitment of AUD\$1 million. In the same month, researchers at the University of New South Wales reported that Australians dramatically overestimate the number of people taking ice in Australia (NCPIC, 2015). The relationship between these two phenomena - the political and the public - is the subject of this article, in particular as it is enacted in policymaking about alcohol and other drug (AOD) use. ${ }^{1}$ How does policymaking conceive of the public to which it must relate and respond? How does its role relate to political forces and contingencies? How do the assumptions made about publics shape or limit public policy and public understandings of social issues, and what if anything can be done to allow more productive approaches? These are the issues this article addresses, and for which the events described above offer a useful illustration. In conducting our analysis our aim is to illuminate how 'the public' is understood by those tasked with the development and implementation of AOD policy, to identify common assumptions, and to go on to consider alternatives to these assumptions that could open up scope for the design and delivery of more innovative, more productive and more equitable AOD policy.

It is by now widely acknowledged that AOD policy is developed within complex networks of social, economic and political forces. One of the key ideas informing these forces (evident in the policy events described above) is the notion of the 'public' or 'publics' of AOD problems and the policy solutions to which they relate. To date, however, very little scholarly attention has been paid to notions of the public in AOD policymaking. This article explores this area 
via a large qualitative research project. Taking AOD policy in Australia and Canada as its empirical focus, and interviews with senior policymakers and service providers in each country as its central method, the project compares key concepts shaping AOD policy in each national setting. In collecting the data, the project found participants relied heavily on notions of the public. For these professionals, the public is a central organizing concept shaping their work. We make this emphasis on the public the focus of this article, turning to the work of Michael Warner, whose influential theorization of publics offers valuable tools for bringing to light the place of publics in thinking about policy development and for analyzing the assumptions behind this thinking. In our analysis we note that public opinion and public understandings of AOD use are commonly cited as key agents in the development and implementation of policies. But precisely how are publics articulated in these formulations? We explore this question in detail, arguing that publics are generally presented as pre-existing groups who need to be managed: contained or educated, to allow policy to proceed. We consider the implications of an alternative formulation, one suggested by Warner's work, that sees publics as made in policy processes, rather than preceding them, and conclude by reframing publics as emergent collectivities of interest. This shift, we argue, creates much needed room for different engagements in the policy process, and in principle at least, greater scope for more innovative AOD policy. In closing, we briefly consider the widely accepted model of good policy development, that of 'consultation', arguing that, if publics are to be understood as emergent, and therefore policy's opportunities as more open than is often suggested, a different model may be required.

\section{Background and literature review}

Alcohol and other drug consumption is widely considered to be the origin of a range of serious health and social problems (Fraser, Moore and Keane, 2014). Governments act on this 
formulation by devising a range of prevention, education and treatment measures, all of which are the subject of intense public scrutiny and controversy. This scrutiny and controversy takes particular forms depending on national setting, but it is also shaped by broad international forces and histories that produce shared ideas and practices across national boundaries. Aiming to examine in detail some of the unique and shared processes and ideas involved in the development and implementation of AOD measures, this article focuses on two countries: Australia and Canada. Very different nations, Australia and Canada also share important similarities. Both countries were early adopters of harm reduction (Ritter and Cameron 2006), and both are regularly ranked highly in overall standard of living (Tiffen and Gittens, 2004; Harchaoui and Tarkhani, 2003) while sustaining significant pockets of marginalization and disadvantage in relation to drug use (Pennington, 2010; Ritter, Lancaster, Grech and Reuter, 2011). The similarities between the two nations suggest they have much to learn from each other, yet AOD-related research collaboration and exchange of information and best practice activity is extremely limited.

The differences between the two countries - for example Canada's bilingualism, its much higher estimated rate of HIV among people who inject drugs (Ritter et al. 2011: 26), its shared border with the US, and each nation's different engagements with their indigenous populations and the AOD issues found in indigenous communities (Gray and Saggers, 2009) - also offer important opportunities for learning and exchange. For example, Sydney and Vancouver both host supervised injecting facilities which emerged out of extended, at times bitter, processes of political contestation (van Beek et al., 2004; Strathdee et al., 1997; Rance and Fraser, 2011; Yamey, 2000; Gandey, 2003), but manage and respond to public scrutiny differently. To date no literature has been produced that could illuminate these differences, or the similarities the two countries share, and the opportunities they offer to the AOD field 
(Kimber, Dolan et al., 2003). This article does not offer a comprehensive comparative analysis of both nations' policy frameworks (for some comparative analysis of the Australian policy, see Moore, Fraser, Törrönen and Eriksson Tinghög, 2015), or of the concepts of the public at work in each (the latter because our qualitative datasets are by their nature not 'representative', so not suitable for this kind of analysis). Instead, it examines some of the shared ways 'publics' circulate in policymaking imaginaries across both countries. In conducting our analysis we find striking similarities that have major implications for conceiving and implementing new, potentially more productive, AOD policies in both countries.

By way of context, however, a few key observations can be made about the two national policies (or 'strategies'), their similarities and differences. It is notable first that Canada's National Anti-Drug Strategy was developed under a Conservative government but is now administered by a progressive (Liberal) government. The reverse is the case in Australia, in that the Australian strategy - the National Drug Strategy (2010-2015) - was developed under a progressive (Labor) government but is now administered by a conservative (Liberal) government. While Canada's strategy focuses only on illicit drugs (facilitating its firmly negative title), the Australian strategy takes a relatively broad approach to its subject in that it includes tobacco and alcohol in its remit. Doing so is significant because it signals a certain liberal willingness to recognize that the lines currently drawn between those drugs stigmatized as scandalous or shameful (i.e. illicit drugs such as heroin or methamphetamine) and those considered normal (i.e. alcohol) are arbitrary. Also, the Australian document adopts the language of dependence rather than addiction, signaling, at least in Australian discourse, a medical approach and the implicit goal of reducing stigma around drug use. The Canadian document is much more mixed in the tone it strikes. Its language is that of addiction and 
dependence, and overall the document, ratified after what Wodak (2008) has identified as a conservative turn in Canadian drug policy, takes neither a consistently liberal approach nor a consistently conservative one.

Beyond brief observations of the kind made above, little comparative discussion has occurred on Australian and Canadian policymaking, but a substantial field of local AOD policy analysis exists in both countries. This work covers a range of different areas. It includes analyses of the effects of national policies and policy changes (e.g. Khenti, 2014; Ivsins, 2011); work on particular aspects of policy and service provision such as needle and syringe programs (e.g. Strike, Myers and Milson 2004); different approaches to AOD use including harm reduction (Roe, 2005; Quirion, 2003); and policy approaches more generally (Ritter and Bammer, 2010; Wodak, 2008; MacPherson, Mulla and Richardson, 2006). Rarely discussed in such research is the role of 'the public' (or 'publics') in policy processes. Much work examines the extent to which the voices and concerns of affected populations are taken into account in the policymaking process. Also examined are the ways policymaking can be made more inclusive (Lancaster, Sutherland and Ritter, 2014; Lancaster, Ritter and Sutherland, 2013; Mathew-Simmons, Sunderland and Ritter, 2013; Kerr et al., 2006; Jürgens, 2005). Other related research examines levels of public support for specific policies through empirical analyses (e.g. MacDonald, Stockwell and Luo, 2010). This research constitutes a valuable contribution to knowledge, but does not consider a number of important questions, including ones that we aim to take up in this paper.

Alongside this research has developed a range of critical approaches to the study of policy and policy activity. This body of work includes a critique of calls for 'evidence-based policy', arguing such calls are insufficiently critical of scientific objectivity, and inattentive to the 
contested and complex nature of science (e.g. Stevens \& Ritter 2013; Ritter, 2011). Other critical work emphasizes the socially constructed nature of the policy endeavor (Lancaster, 2014). In their recent work on methamphetamine, Moore and Fraser (2015) call for even more critical AOD policy research, and it is clear that some of this work is already underway. In recent years, for example, researchers have developed an interest in poststructuralist approaches to policy, with the work of Australian poststructuralist theorist Carol Bacchi (2009) being particularly influential (see Fraser and Moore, 2011, for the first known use of Bacchi's work by researchers working in the AOD field).

Applying the Foucauldian notion of problematization to the study of policy, Bacchi observes that 'problems' do not precede the policymaking process but instead are constituted through it. The importance of this observation is that it allows us to examine how apparently commonsense assumptions and ideas come to be formulated and then fixed within policy frameworks, drawing attention to the ways these formulations open up or foreclose particular solutions. Much of the work that draws upon the 'problematization' framework focuses on the way that AOD policy shapes subjects and objects, such as the claimed 'problems' of amphetamine-type stimulant use (Fraser and Moore, 2011), 'alcohol-fuelled violence' (Lancaster, Hughes, Chalmers and Ritter, 2012), alcohol-related harms (Bacchi, 2015), and the drug-using subject and the object of 'recovery' (Lancaster, Duke and Ritter, 2015). Some work also examines the ways policy problematizations change over time (Lancaster and Ritter, 2014). Recently, Bacchi’s approach has been extended and adapted to aid in examining legal and regulatory processes, for example, to consider how these processes problematize 'addicted' subjects (Seear and Fraser, 2014) and the criminalized object of the syringe (Lancaster, Seear and Treloar, 2015). 
Collectively, this work makes an important contribution to our understanding of the ways policymaking processes constitute alcohol and other drug-related subjects ('addicts', people who use AOD) and objects (syringes, AOD-related harms). Importantly, however, it says little about the relationship between AOD policymaking and publics. While, as we noted earlier, a growing body of work explores the ways publics might be brought more actively into policymaking endeavors, our concern here is with a different issue. Following Foucault's notion of problematization and the literature that has built on it, we ask how policymakers and service providers (those tasked with creating and implementing policy) conceptualize the 'publics' for whom policy is made. What assumptions do policymakers make, if any, about the nature of publics? As with policy problems, we find a widespread tendency to treat publics as anterior to policy: as the foundation for, and limit to, policy options. There is no doubt that policy is in part constituted through publics and the assumptions made about their interests and convictions, as former Australian Prime Minister Tony Abbott's initiative suggests. Our aim is to attend to the reverse, heretofore neglected, issue: the way in which publics can be said to be constituted by policy. As will become clear, publics, their demands and their perceptions, often feature in accounts of policy activity, shaping what is said to be possible, often foreclosing particular ways of dealing with AOD issues.

\section{Approach}

In conducting our analysis we draw on the work of Michael Warner, in particular his 2002 article 'Publics and Counterpublics', which offers useful tools for conceptualizing the relationship between policymaking and society. What is the relationship between policymaking and the population affected by the policies in question? What are the responsibilities of policymakers and publics, and what kinds of agency are available to each? 
What is public discourse and how does it operate? These questions also play out over and over in the data analyzed in this article.

Michael Warner's innovative poststructuralist analysis of public speech and the political dynamics of public discourse has been widely embraced by scholars of social movements and political change. The work was initially developed in the context of the politics of gay rights, in which conventional liberal approaches to political subjectivity and change had already attracted criticism as narrow and essentializing, circumscribed by simplistic identity politics and its exclusionary tendencies (see Fraser, 2006). Warner's approach offered a way of explaining the development of shared perspectives without assuming underlying shared values or experiences - in this way it offered a highly productive and timely queer account of politics. More recently, Warner's work has been employed in AOD research (see Race, 2009) where its capacity to account for political patterns, forces and change without homogenizing those involved has been of equal value. This article draws on Warner's highly original and influential approach to shed new light on the assumptions policy makers, service providers and advocates make about the publics of drug policy.

According to Warner, public discourse does not merely address 'the' public. Instead it postulates particular individuals, publics and even worlds. But this does not occur through a narrow top-down action of force. Publics emerge spontaneously in attending to public speech, they respond to and circulate this speech, operating within subtle but important bounds implied in the speech. This is how worlds are made and remade. As Warner says (2002: 114): Public discourse says not only 'Let a public exist' but 'Let it have this character, speak this way, see the world in this way.' It then goes in search of confirmation that 
such a public exists, with greater or lesser success - success being further attempts to cite, circulate, and realize the world understanding it articulates.

Discussions of the exact nature of publics and how they are enacted are important for our analysis because they shed light on a phenomenon that, as we will see, tends to be taken for granted by those who see their work as subject to the will of publics. According to Warner, publics emerge in response to public discourse, are complex and spontaneous, but are always to some extent shaped by the subtle parameters of that public discourse. This notion of multiple, emergent publics has been taken up productively in a range of empirical studies. For example, in a study of vaccine refusal, Lawrence, Hausman and Dannenberg (2014) conducted qualitative interviews with parents who had declined permission for their children to receive a flu vaccine offered in a school-wide program. Public health experts assumed a pre-existing 'anti-vax' public, and presumed to know the reasons for the refusal, but the study found instead a series of local publics, emerging in response to both the specific program and to broader public discourses of immunity and health. In the case of AOD policy publics, we can say they are framed by the traces of other past and concurrent AOD publics: publics of the pharmacology, psychology and neuroscience of drug effects, the outlaw status of some drug consumption, the stigma of addiction, the demonization of particular drugs (such as 'ice'), and so on. As Warner might argue, drug policy does not simply address or reflect the public. Instead it actively produces particular publics of drug use.

In this formulation is reflected a central question about publics and their relationship to public discourse: cause and effect. Warner puts it this way (2002: 50):

A kind of chicken-and-egg circularity confronts us in the idea of a public. Could anyone speak publicly without addressing a public? But how can this public exist 
before being addressed? What would a public be if no one were addressing it? Can a public really exist apart from the rhetoric through which it is imagined?

This question cannot be resolved by choosing one of the two options proposed. Public discourse and publics - here AOD policy and the publics that engage with it - act on each other in a process that cannot be unpicked in any simple way. Publics are self-organized; at the same time they depend on public discourse for their existence. This complexity is, in Warner's view, one of the sources of the power of publics:

the modern sense of the public as the social totality in fact derives much of its character from the way we understand the partial publics of discourse, like the public of this essay, as self-organized...It is self-creating and self-organized, and herein lies its power as well as its elusive strangeness. 51

What does Warner mean by this idea of power? To begin with, he points out that liberal democracies rely upon the idea of independent self-organizing publics that cannot be controlled from above, either by virtue of governance or by virtue of economic power. If they could be controlled in such a way, a fundamental constituent of our narrative of a free society would be lost. So it is essential for our story of liberal democratic freedom that our processes of deliberation and decision-making entail self-organized publics, participating in such discourse and able to influence it, either by debate or by the ballot box. Inherent in this formulation of publics, however, is instability, and the difficulty in predicting public opinion and action. Warner points to polling as a key means by which stakeholders aim to contain this instability, to direct or resolve it. Yet polling itself is part of the public discourse that posits as much as addresses publics (the very publics it purports to study). 
Publics have to be understood as mediated by cultural forms, even though some of those forms, such as polling, work by denying their own constitutive role as cultural forms. (2002: 53-4)

The picture Warner offers here is one of a seemingly continuous (potentially productive) process of confusion underway in public life, one that habitually mistakes emergent publics for independent, pre-existing collections of individual persons (2002: 58). As we will see later in the article, this confusion has costs. Adding to his picture, Warner also notes that public speech must be more than individual texts. Instead, it comprises the interplay of many texts, and in this respect a public can perhaps be better understood, Warner says, as 'an ongoing space of encounter for discourse'. In other words, it is not individual texts alone that create publics, but 'the concatenation of texts through time' (62). Once a public is constituted in this continuous process of speech, citation, encounter, it is then treated as a given 'social entity' (64). In this much-expanded capacity, publics, and thus public speech take part in the making of worlds (64).

This final point is especially important for Warner's approach. Publics are postulated by public speech but are commonly granted the status of anterior social entities. Seen in this way, they come to be credited with the power to act, indeed, seen in this way they inevitably do act, helping to make worlds. This 'world-making' capacity must, however, also be seen in light of the constraints under which publics come into being and operate. For while Warner emphasizes the sense in which publics emerge through public speech, and as such can be said to be self-organized, this does not mean they are limitless in the forms they may take, the terms they may use, or the territories they may traverse: 
It appears to be open to indefinite strangers, but in fact selects participants by criteria of shared social space ... habitus, topical concerns, intergeneric references, and circulating intelligible forms ... These criteria inevitably have positive content. They enable confidence that the discourse will circulate along a real path, but they limit the extension of that path. (2002: 75-6)

In short, the publics brought into being by public discourse are necessarily effects of power in that discourse is always already itself uttered in power. Here we are reminded of the public of the 'ice epidemic', a public invited to participate in public life in a highly specific way via a series of highly specific assumptions: by 'dobbing in' a drug dealer. Public speech thus elaborates particular cultures, and as Warner adds, these entail particular ways of life with specific ethics, class and gender dispositions, and forms of economic organization (2002: 76). Wherever a public is taken to be the public (as with polling data), those particularities come to order the political world in invisible ways (2002: 77).

In sum, Warner's theorization of publics brings into focus several key issues for our analysis. First, while publics are commonly thought to precede public speech, a 'chicken and egg' dynamic more productively describes the relationship between the two. Origins and effects are difficult to unpick here, raising questions about scope for action in relation to publics and their perceived dispositions. Second, the publics enacted in these complex dynamics are elusive and unstable, not least because a certain imprecision exists in the extent to which publics are seen as accumulations of, or overlapping with, concrete individuals. This instability and elusiveness suggests opportunities for reworking (with) publics. Third, if publics are enacted in public discourse, practices purporting to investigate and fix public opinion - such as polling - must be rethought. Likewise, 'public opinion' should be reconceived as enacted in processes of public address. Fourth, the publics spontaneously 
brought into being by public discourse are effects of power. Their spontaneity should not be misrecognized as autonomy or freedom from the constraints of politics. Indeed, the legitimacy of particular publics is established by the mode in which public discourse is articulated, rendering some publics more likely to be treated as the public, with all the political implications and privileges this entails.

Understanding publics this way illuminates a range of themes found in the data collected for this analysis. Most obviously, in actively theorizing publics, Warner alerts us to the need to treat the public as a theoretical construct lending itself to different approaches. This, in turn, opens up for scrutiny the implicit and explicit approaches to publics mobilized in participants' statements. In addition, his work invites us to ask questions about the particular publics assumed in participants' statements, how they are enacted, and what they mean for how the possibilities of AOD policy are understood.

\section{Method}

The project on which this article is based was designed to explore the ideas and assumptions shaping AOD policymakers' and service providers' work. It gathered data in two countries as a means of casting widely and looking for fertile differences able to improve responses in both countries. In total the project collected 60 qualitative interviews with senior AOD policymakers and service providers, spread across two national sites: Australia - Victoria $(n=20)$ and New South Wales $(n=20)-$ and British Columbia, Canada $(n=20)$. The interviews were collected in three phases. The first phase, Victoria, Australia, was conducted as a pilot study in 2011, and the second and third phases, NSW, Australia and BC, Canada, were conducted in 2014. In each site a variety of professionals working in the AOD field 
(government and non-government policymakers, senior service providers in harm reduction and treatment services, and representatives of advocacy groups) were interviewed.

The interviews used an open-ended interview schedule in which participants were asked about the nature of their work, the issues they deal with in their day-to-day activities, their understanding of key concepts in the field such as addiction and recovery, and the approaches, tools and models they rely upon as well as those they consider unhelpful. The interviews were on average approximately an hour in length. Interviews were conducted by a team of researchers, all of whom were trained qualitative interviewers. Prior to data collection the interviewers discussed the interview schedule in detail with the project's lead investigator (Anonymised) and read previous project interviews where available. After initial interviews were conducted each interviewer received feedback from the lead investigator to help ensure the focus of the interviews, follow up questions and other aspects of the process were conducted with consistency across sites and between interviewers. In this way a consistent approach to data collection was achieved.

The interviews were anonymized and given pseudonyms. They were then transcribed and coded thematically using NVivo. The themes were identified using a combination of methods: some arose from the literature and the questions it poses about concepts of addiction and how they are mobilized, and some were derived directly from the interviews themselves. The project was granted ethics approval by the Curtin University Human Research Ethics Committee (\#HREC 37/2013).

\section{Analysis}


As already noted, the interviews analyzed here often refer, both directly and indirectly, to the public of drug policy. In the discussion below we analyze these references, identifying three main ways publics are framed: first as an entity that largely controls policy, but is uninformed and as such an impediment to good policy; second, as the object of management by elites who ultimately control policy; and third, as specialist knowledge communities with a particular privilege to contribute to policy beyond the general public. Our aim is to illuminate how publics of drug policy are understood by those tasked with its development and implementation, to identify their common assumptions, and to go on to consider alternatives to these understandings that could open up scope for the design and delivery of more innovative policy.

\section{Managed publics}

The first mode in which publics are articulated in our interview data is one of deficit and caution. Here the public is understood to be poorly educated on AOD matters, governed by their emotions and resistant to change, especially where this would result in less punitive responses, and, as such, a source of fear among politicians and a brake on good policy. As Eve (Policy, Victoria, Australia) says of her own role,

Part of the biggest challenge is, I think, is [...] walking that line between providing advice to Government and, you know, governments who are elected on their policy platforms and they're influenced by both community sentiment and, you know, obviously, a government position.

Eve goes on to elaborate on this view, explaining:

And part of it is about what, what the community will bear in terms of level of interference, if you like, in people's lives... what government can and can't do through its legislative processes, and what's about education. What is the role of government, 
$[\ldots]$ in trying to both protect the community but allow the freedom of the individual? In these comments we see considerable caution expressed in relation to public views on drug use and government responses to it. Community sentiment precedes policy action here. It is the 'chicken', let us say, to policy's 'egg'. We might also take note of the different terminology in the two statements as it relates to this chicken. While the first participant refers to society and people, the second refers to community. These are rather different entities conceptually speaking, more about which will be said later.

How is this public of AOD policy to be managed? A BC, Canada, participant, Doug (Policy), explains the process in this way:

[It's about] getting out there and talking with, number one, the broader public, with some ideas for where you might like to go and testing it - vision. What is your vision for the system in the long run? Where would you like to get to? Does that echo? Does that make sense? Does that translate for people in terms of themselves and their families and their lived experience or not...

Here, policy proposals are tested in meetings with the 'broader public' to find out whether they fit existing public perceptions and experiences. This account is similar to those - noted earlier - that describe the need to examine levels of public support for specific policy measures (e.g. MacDonald, Stockwell and Luo, 2010). According to Doug's approach, the knowledge and opinions of publics, whether well-informed or otherwise, occupy a central place in the development and implementation of public policy. Interestingly, this process is also to some extent dependent upon whether the issue in question registers for publics as a significant one, whether it warrants problematization at all:

How much concern is there with the public? So, how much are we reading in the newspaper? What did the poll say? What kind of public interest is there in this area, 
because there is an endless series of issues and problems that government could be wrestling with. And you want to make sure that they are wrestling with issues and problems that the public is also wanting to wrestle with. (Doug, Policy, BC, Canada) In this account, governments problematize phenomena where publics they 'consult' indicate they should. They also take their lead from these publics as to how this problematization can play out and what kinds of problems the phenomena can be said to be. What kinds of forces shape public views? According to Eve (Policy, Victoria, Australia), emotions rather than information can take the lead:

I remember [during the early] 2000s when there was a lot of injecting drug use and a lot of debate about what types of services were required [...] the community [was split]: whether it be huge tolerance, for example, in the areas where I lived, and huge intolerance in other areas. So you know, part of the problem is that it's a very, it's a very emotive debate and will continue to be.

For some, the public's response to drug issues stands in contrast to its response to other issues, creating significant disparities in resourcing. As Jane (Service provision, Victoria, Australia) puts it,

And we look at with envy some of our general medical treatment service providers [servicing] heart disease or cancer treatment, because they're high profile areas which everyone relates to, you know, that you can actually get the public on board a bit more. They've all got money coming out of their ears.

Here public spending is at least in part guided, or curtailed, by the presence or absence of the emotion noted by Eve: public empathy and support. If the public is not seen as 'relating to' drug use issues, governments will be less inclined to invest in them. 
In keeping with this assessment of policymaking and implementation processes, in which public relations govern politicians' decisions, some participants focus on the ineffectiveness of research evidence in shaping policy. Where the public is understood to have fixed views resistant to persuasion and change, and elected officials lack the confidence to confront this resistance, evidence is likely to be ignored. As Bridget (Policy, NSW, Australia) observes: No, it isn't easy working in a public sector in government. I mean, health policy is equally about the political context as it is about evidence and everything else. I don't think that you can operate in a place like the [government department] and just look at - the evidence is a really important part of it, but the political is almost, almost everything.

Edmund (Service provision, BC, Canada) makes a similar point:

There's the whole political ideology that exists around addiction and the drug war and how, you know, we need to keep drugs out of hands of addicts and, you know, we have to do something. We have to lock these people up. That whole kind of philosophy that has absolutely no evidence. In fact, the evidence shows exactly the opposite, but it is so ingrained in people's belief and is often [adopted by] the political leaders if that's the belief of their constituents.

As above, strong public opinion is cited here as an obstacle to developing good policy based on evidence. Precisely how public opinion comes into being or is shaped is rarely directly discussed in the interviews, as is how policymakers identify what the public's opinions actually are, although references to the media and its facile or sensationalist treatment of drug issues are sometimes made. As Geoff (Service provision/Policy, Victoria, Australia) explains: The way in which some of these issues are dealt with are often done in a fairly populist way rather than looking at the intricacies and the nuances of the issues. That provides some great challenges for advocates to try and get the point across in terms 
of what's required. And I think it provides challenges to the politicians to also not succumb to a times aggressive media that's able to push a line and lose [them] some votes.

One BC, Canada participant, Raymond (Service provision), goes even further than this, suggesting that politicians are not only obliged to grapple with media agendas or other cynical forces, but themselves cynically act to shape such forces (as might be argued in the case of Australia's 'Dob in a drug dealer' initiative), working to create, for example, the 'evidence base' they prefer:

I'm sometimes thinking it's our federal government's ideology-based evidence at play on, it's not evidence-based decision making, its ideology-based evidence making or something like that. But how do you get rid of that ideology and just kind of concentrate on what we need in the toolbox, and we need a whole bunch of tools... In Raymond's view, responding to drug issues requires a range of strategies, some of which are politically more palatable than others, and 'evidence' is one of the logics through which justifications are made about which strategies are taken up by governments and which are ignored (see also Ritter, 2011). Other participants offer alternative (although potentially overlapping) accounts of this process, pointing to the significant differences of opinion within the AOD sector as a reason why government policy does not straightforwardly mobilize evidence. As Australian participant, Louis (Service provision, NSW, Australia), explains, We are a fragmented sector, in a way that other sectors [are not]. While they may be just as fragmented, they have learnt a long time ago to pull their heads in and present a good public face and get the money. You can have the arguments behind the scenes but the ongoing spats often in public between the abstentionists, the harm reductionists, the naltrexone-ists, the heroin programmists, the consumer groups, the 
professionals, the psychologists [who] hate the doctors, the specialists [who] hate the GPs, all that in fighting has really, really not done us any services, because it is often done in a semi-public forum, and not that people contact the Herald Sun [a conservative newspaper], but it is often done at government level. Governments get a sense that the sector itself does not know if it is Martha or Arthur...

From this point of view, policymakers may come to see clinicians, advocates and other policy professionals as in need of education just as is the broader public whose views their work must navigate.

In this section we have presented material demonstrating the widespread discussion in our interviews of the public of AOD policy, its relationship to policy discourses, and its role in the decisions that are made about policy. We have suggested that this approach focuses on the 'chicken' side of the binary model taken for granted in accounts of public discourse: the public is the chicken that lays the egg of public discourse. Yet these statements also introduce some important inconsistencies, multiplicities and discontinuities. Participants refer to the public, the community and to the society. Although different, each fulfills a similar function in the accounts given, introducing an external, non-expert population that limits policy potential primarily, though sometimes implicitly, through its voting potential. Yet each of these modes of framing the population has different implications: the public is anonymous and massive (Warner, 2002). The community has group rights, even if it is 'split' as described above. It is a notion that implies belonging and the expression of emotions (Joseph, 2002). Society also allows for emotions: it is a collective of people who might, it seems, lose its 'compassion'. Considered from the point of view of Warner's approach, however, all three modes share a key assumption: public, community, society: whatever this population can be said to be, it exists independently of the policy discourse in question. It precedes it, and 
therefore has the potential to allow or disallow it, because the public, the community and the society can collectively bestow or confiscate the power politicians have to enact policy at all.

\section{Educated publics}

A second main way policy is understood to develop and publics are understood to figure is in a relation somewhat the reverse of that described above. In this approach, the job of politics is to educate publics rather than merely react to, or satisfy, public concerns. This approach shares much with mainstream approaches to 'science communication' which tends to treat public opinion as the effect of a deficit of scientific knowledge and open to change by the provision of scientific information (see Brown, 2009; Wynne, 2006). Implicit in this approach is the idea, as in the previous formulation, that education constitutes a one-way relation in which the public is uninformed and as such an obstacle to enlightened policy. In one account, from Jess (Policy, BC, Canada), both elected officials and members of the public must be guided by policymakers lest unworkable or ineffective policies, driven by 'panic', are proposed and implemented:

Our branch, when approached about a Crystal Meth Strategy, said "no we do not focus on singular drugs, we look at the broad range of substance use and we see that policy across the board is useful". And then I think it was the Attorney General or another ministry that took it [the Crystal Meth Strategy] up and we kind of went along to make sure that there was some semblance of sanity in it, but they formed a crystal meth secretariat and they gave money to these very vocal citizen groups and municipal officials and, really, it was a classic panic. 
This role does not mean that policymakers are able to control the process or outcomes however. As Jess goes on to note: 'in some ways we had to kind of jump on the band-wagon because it was going to go ahead anyway without us so how could we put some semblance of sanity in it.'

NSW, Australia participant Lance (Policy) also describes a process that seeks to engage a range of stakeholders in order to educate and guide outcomes towards the most effective and informed. In this case, as above, it is policymakers who are best placed to decide on good policy, and they must manage and educate the public, as well as other stakeholders at times: So we recently had [an amenity] problem with a private clinic here in Western Sydney and we worked closely with the local hospital district, their private clinic, the local member, the local council, and the local police, in order to try and reduce the issue [...] There was concern around, you know, people congregating in front of it and harassing people trying to access the local shopping district [...] also working with the local community to try and manage the situation, and also trying to communicate to people that this is a public health response and people have a right to treatment. They're not necessarily causing all of the issues in the community. Trying to educate people, not always successfully, but you have to work with the local communities.

In some cases described by the participants, policymakers must manage both politicians and the public to produce policy that satisfies all parties and yet is also effective. As above, the role of evidence here is an uncertain or contested one:

So, umm, the job of this sort of frank and fearless bureaucracy, how, how do you, ah, be the best you can be in this space by bringing along publicly elected officials who 
are elected to make those decisions, have every right and every place in our system to be making them, and then with a community view that do not always align. So, you know, the best evidence does not always align with what the community believes we ought to be doing which doesn't necessarily always align with what a government is prepared to endorse. (Celine, Policy, Victoria, Australia)

Eve (also Policy, Victoria, Australia) makes a similar point, in this case emphasizing the need for policymakers to seize the initiative when circumstances suggest good policy opportunities not necessarily recognized by the public or by elected officials have become available:

It's about trying to both be anticipating and opportune about what can be done at certain times. For example, there does seem, after years of campaigning around prescription drug abuse, there does seem to be a kind of groundswell of interest and concern at the moment and it's being able to harness that.

While a number of participants offered accounts of the policymaking process that suggested politicians were not always best equipped to identify good policy responses, at least one went further, arguing that politicians actively harm good policymaking by playing issues for political gain. As BC, Canada participant Edmund (Service provision) said, [The message to the public from the Conservative government was]: "You need to support us as we prepare for the next election [...] because if you elect liberals or the NDP", which are the two other parties, "they are going to put heroin in the hands of heroin addicts, and only we will stop that." And they sent that out broadly through the entire country to gain support even though the evidence of course, does not say that at all, nor are we giving heroin to heroin addicts anyway. But, you know, the ability for 
the political party to harness that as a galvanizing force to drive membership and support so they can become re-elected, severely impedes our ability to advance.

\section{Consulted publics}

The third category of approaches to the public identified in the data was a much smaller one: a few references are made to particular communities and their capacity to inform policy and enable better policy adherence. This approach allows a reversal of the formulation of expertise assumed in the previous two categories: here policymakers and other expert decision makers can genuinely learn from local knowledge, rather than just manage it. This is, however, presented as an exceptional state of affairs, generally related to specific identitybased publics (Aboriginal communities, migrant communities). As Eve (Policy, Victoria, Australia) explains in relation to a consultation that was held with the Victorian Somali community about the use of khat,

And so [the researchers we contracted] went and spoke or set up meetings and groups with the community and that provided us with some really good solid information and advice about how it was being used and the number of people in the community who were using it, including how it was being managed, who was using, whether it was identified as a problem and what some of the community thought some of the issues [...] that needed to be dealt with. And as a result, the community made recommendations to Government [...] Elements [in the community] had argued that they wanted it to be banned but they then advised Government they would prefer to see whether [...it] would be divisive within the community, and [instead] be looking at maybe restricting the amount that could be imported...

Here the Somali community is conceptualized as a distinct or bounded group: identified, engaged and consulted such that policy proposals are understood to arise from the community 
itself. A similar account is given in the case of policy around alcohol consumption in a particular indigenous community:

And so we did a community consultation, using [...] a consulting firm that was established by Aboriginal people and so using community members to go and talk to communities [...] It's recognizing that this is a hard-to-reach group and we need to be able to try and have very tailored responses that really do meet community need.

In both these examples, specific communities organized around ethnic identity are engaged and their perspectives on the drug issues judged to be of special relevance to them are accessed and addressed. In relation to the first example, Eve also notes that community opinion was divided and that it changed over time. So these communities are not necessarily conceived as homogenous, indeed part of the role described by the participant is one of managing and bringing to resolution differing views within a community. Yet, as with the previous two categories, these communities are understood to precede the consultation process. Given they involve negotiation of difference, this is perhaps an especially compelling example of the potential for policymaking (here in the form of community consultation) to enact the very communities to which it seems to attend.

\section{Reconstituting publics of AOD policy}

The interview material presented here illuminates the many different positions the public is ascribed in the accounts and practices of those tasked with developing and implementing AOD policy. For some, publics play the key role in determining what form a policy may take. For others, they must be navigated so that more informed stakeholders can also play a part. In a few, quite specific, cases, they are genuinely useful and knowledgeable participants in the policy process. As we have argued, however, across all these different perspectives can be 
traced a common thread: the idea that publics exist independently of the policymaking process, as stable external communities, societies or other collectivities. The implications of this widespread assumption are significant in the context of AOD policy, perhaps most obviously because they take as given opinions and dispositions many participants see as at odds with good policy. In this sense they inevitably act to circumscribe the imaginary of better policy, allowing, if not always necessitating, questionable policy measures of the kind described at the outset of this article.

It is one thing, however, to identify this assumption in the policy process, and another to articulate how we may take a different view, one perhaps inspired by Warner's incisive critique. Yes, we can identify the apparent dilemma of the chicken and the egg, recognize the instability of the publics otherwise taken to be so fixed and truculent, and point out that these publics are not free of power but instead are its effects. We can draw on Foucault's terms and say that policy is actually part of 'a set of discursive and non-discursive practices that [...] constitutes [the public] as an object for thought' (1988: 258). Our participants, however, might argue in response that whatever such claims made, in practice publics do appear very robust, and that grappling with what 'the public thinks' remains one of policymaking's primary challenges. Comments of this kind would be understandable but would also benefit from historicizing. As Adams and Hess (2001) point out, Australian governments have really only taken an interest in the connections between publics (or as they are sometimes styled, 'communities') and the policymaking endeavor since the late 1990s, as a result of a complex convergence of factors (see also Crase, Dollery and Wallis, 2005). ${ }^{2}$ So while publics and their views are imagined to be one of policymaking's self-evidently primary challenges, it is worth bearing in mind that this is a distinctly contemporary concern. From this point of view, given the relative novelty of present, seemingly commonsense, assumptions, it does not seem 
unrealistic to propose another rethinking of publics; to move beyond conventional critiques of consultation processes as tokenistic or faddish (e.g. Arnstein, 1969) to a more ambitious reconceptualization of the imagined publics of the policy endeavor.

At this point it may be useful to revisit the chicken-and-egg figure, for in it might lie a key to opening up this issue. Wheresoever appears a binary choice - the chicken yields the egg, the egg yields the chicken - can be found the hidden or disavowed excess to this binary. It would be no great innovation to say this excess can be found in power, which acts in innumerable ways, across multiple dimensions, in predictable and unpredictable ways. This is especially applicable to the knowledge-making such as polling or other research that gives some kinds of formal meaning and shape to publics (as noted in relation to our opening vignette and in our discussion of Warner's work). Indeed, the AOD field is one in which questions of public opinion are frequently researched (e.g. MacDonald, Stockwell and Luo, 2010). Typically this research is based upon the same assumptions as can be found in our interviews: an anterior public is posited, one with a fixed set of opinions that policymakers and others must either discover and cater to or disregard at their peril. ${ }^{3}$ Yet some studies have shown that an understanding of these publics more in keeping with Warner's is not only plausible but practically valuable. As Treloar and Fraser (2006: 358) argue in addressing policy reticence around needle and syringe programs (NSPs), the ways in which research is conducted, the form of questions, the context of research and the background to polling provided, all act to shape participant responses. Thus are the publics of NSPs made and remade in their circulation in research, into the media, policy and beyond. What is 'known about publics' is, it seems, always open to question. So too is our assumption that such publics (the 'vocal critics of NSPs') exist before they are researched. Indeed, they may be, this discussion suggests, available to remaking in a way that we see from time to time arise, suddenly and 
apparently unaccountably, in major historical shifts, depending upon the emergence of a new kind, or mechanism, of address.

Insofar as knowledge-making can be said to produce certain defined publics, it does so at the expense of others. More critical interrogation of polling and other public opinion research is warranted here, with more attention paid to the ways such research treats as pre-existent some entities (publics, opinions) that instead it calls into being itself. Policy too could benefit from this kind of rethinking. Here we offer a reformulation of recent work on 'communities' of policy as a possible way forward. A growing literature on participatory democracy points to the potential for 'ground up' and local governance exercises as a means of solving policy problems and increasing opportunities for people to participate directly in decisions that affect their lives (Gaventa \& Barrett, 2012; Walden, 2015). Much of this literature emerged from global development contexts or arose for specific purposes, such as the need to address the exclusion of marginalized groups from governance processes. Important in many respects, this work does not, however, serve our purposes in that it tends to treat these groups as stable communities even as it questions the capacity of conventional democratic processes to engage them. Instead we ask whether it is possible to conceive spaces of consultation in which relentlessly unstable, thoroughly diverse collectivities are thrown up, and their knowledges both aired and opened to revision. Such possibilities begin to emerge if one considers a shift in terms. What happens to the status of such participants, we would ask, if the term 'consultation' is replaced with 'conference'. Hierarchies are less readable here, and stability is decentered in favor of convergence and ephemerality (Temenos, 2015). What might it mean to hold community 'conferences', instead of community consultations, on drug issues? Conferences differ from each other in many respects: industry conferences differ from academic conferences, and both differ from religious conferences. And the term has different 
implications in different national and cultural contexts. Here we are thinking of conferences that arise out of previously dispersed and divergent subjects, that offer a temporary space of convergence around a specific concern, and that take for granted that all participants will emerge from the process of confer-ence changed in some way: will become new subjects-inthe-making. Such a conference could, for example, include the classically excluded 'drug dealer' - rather than 'dobbing' her or him 'in'. After all, the figure of the drug dealer is just as likely to accrue to a public, a community, a society, as any other subject.

\section{Conclusion}

As Warner puts it, a public is 'an ongoing space of encounter for discourse'. It is in this sense that the two interventions we have identified above might respond to the restrictive, at times seemingly suffocating, intolerant or ossified publics of AOD policy conjured in our data: publics routinely ascribed the role of defining and circumscribing responses to AOD use. In this article we have noted that 1) the knowledge-making processes out of which these publics are sometimes conjured cannot be separated from the phenomena they purport to investigate, and 2) our model of consultation might warrant rethinking so that its complicity in the present economy of restriction may be displaced. It is in this last sense that the conference might operate, opening a less restrictive space for the enactment of an ephemeral policy public; one in which 'opinions' emerge, collide, are collaboratively articulated, and speak with the policy process. In such a process can be found a far more complex and promising and fertile relationship than the chicken and the egg's. 


\section{References}

Adams, D. and Hess, M. 2001. “Community in public policy: Fad or foundation?” Australian Journal of Public Administration 60 (2): 13-23.

Arnstein, S. 1969. "A ladder of citizen participation.” Journal of the American Institute of Planners 35 (4): 216-224.

Bacchi, C. 2015. "Problematizations in alcohol policy." Contemporary Drug Problems 42 (2): 130-147.

Bacchi, C. 2009. Analysing policy: What is the problem represented to be? Sydney: Pearson.

Brown, S. 2009. “A new deficit model.” Nature Nanotechnology 4: 609-611.

Crase, L., Dollery, B. and Wallis, J. 2005. “Community consultation in public policy: The case of the Murray-Darling Basin of Australia.” Australian Journal of Political Science, 40 (2): 221-237.

Fitzgerald, J. 2015. "Political fear-mongering just magnifies the harm ice can do." The Conversation, April 10 2015. Accessed online 30/09/15 at: https://theconversation.com/political-fear-mongering-just-magnifies-the-harm-ice-cando39992 
Foucault, M. 1988. The concern for truth (A. Sheridan, Trans.). In L. D. Kritzman (Ed.), Michel Foucault: Politics, philosophy, culture. Interviews and other writings, 1977-1984 (pp. 255-267). New York: Routledge.

Fraser, S. 2006. Poetic world-making: Queer as Folk, counterpublic speech and the 'reader'. Sexualities, 9 (2): 152-170.

Fraser, S. and Moore, D. 2011. "Governing through problems: The formulation of policy on amphetamine-type stimulants (ATS) in Australia." International Journal of Drug Policy 22 (6): 498-506.

Fraser, S., Moore, D. and Keane, H. 2014. Habits: Remaking addiction. Basingstoke: Palgrave.

Gaventa, J. and Barrett, G. 2012. "Mapping the outcomes of citizen engagement." World Development 40 (12): 2399-2410.

Ivsins, A, et al. 2011. "An examination of injection drug use trends in Victoria and Vancouver, BC after the closure of Victoria's only fixed-site needle and syringe programme." International Journal of Drug Policy 23 (4): 338-340.

Jürgens, R. 2005. 'Nothing about us without us'-Greater, meaningful involvement of people who use illegal drugs: A public health, ethical, and human rights imperative. Toronto: Canadian HIV/AIDS Legal Network, International HIV/AIDS Alliance, Open Society 
Institute. Accessed online $4^{\text {th }}$ August 2015 at: www.aidsalliance.org/assets/000/000/376/3101.-Nothing-about-us-without-us-Report-(English)_original.pdf?1405520211

Kerr, T. et al. 2006. 'Harm reduction by a 'user-run' organization: A case study of the Vancouver Area Network of Drug Users (VANDU).” International Journal of Drug Policy 17 (2): 61-69.

Khenti, A. 2014. "The Canadian war on drugs: Structural violence and unequal treatment of Black Canadians.” International Journal of Drug Policy 25 (2): 190-195.

Lancaster, K. 2014. "Social construction and the evidence-based drug policy endeavour." International Journal of Drug Policy 25 (5): 948-951.

Lancaster, K., Duke, K. and Ritter, A. 2015. 'Producing the 'problem of drugs': A cross national-comparison of 'recovery' discourse in two Australian and British reports." International Journal of Drug Policy 26 (7): 617-625.

Lancaster, K., Hughes, C., Chalmers, J. and Ritter, A. 2012. "More than problem-solving: Critical reflections on the 'problematisation' of alcohol-related violence in Kings Cross." Drug and Alcohol Review 31 (7): 925-927.

Lancaster, K. and Ritter, A. 2014. "Examining the construction and representation of drugs as a policy problem in Australia's National Drug Strategy documents 1985-2010.” International Journal of Drug Policy 25 (1): 81-87. 
Lancaster, K., Ritter, A. and Sutherland, R. 2013. "Public opinion and drug policy in Australia: engaging the 'affected community'." Drug and Alcohol Review 32 (1): 60-66.

Lancaster, K., Seear, K. and Treloar, C. 2015. 'Laws prohibiting peer distribution of injecting equipment in Australia: A critical analysis of their effects." International Journal of Drug Policy. 26 (12): 1198-1206.

Lancaster, K. Sutherland, R. and Ritter, A. 2014. "Examining the opinions of people who use drugs towards drug policy in Australia." Drugs: Education, prevention, and policy 21 (2): 93101.

Lawrence, H., Hausman, B. and Dannenberg, C. 2014. 'Reframing medicine's publics: the local as a public of vaccine refusal.” Journal of Medical Humanities 35 (2): 111-129.

Macdonald, S., Stockwell, T. and Luo, J. 2010. "The relationship between alcohol problems, perceived risks and attitudes toward alcohol policy in Canada." Drug and Alcohol Review 30 (6): 652-658.

MacPherson, D. Mulla, Z. and Richardson, L. 2006. "The evolution of drug policy in Vancouver, Canada: Strategies for preventing harm from psychoactive substance use.” International Journal of Drug Policy 17 (2): 127-132.

Mathew-Simmons, F., Sunderland, M. and Ritter, A. 2013. "Exploring the existence of drug policy 'ideologies' in Australia.” Drugs: Education, Prevention, and Policy 20 (3): 258-267. 
Moore, D. and Fraser, S. 2015. "Causation, knowledge and politics: Greater precision and rigour needed in methamphetamine research and policy-making to avoid problem inflation.” Addiction Research \& Theory 23 (2): 89-92.

NCPIC 2015. Ice in Australia: An online survey of attitudes and experiences. Accessed online 17/08/15 at: https://ncpic.org.au/news/ice_survey_report/

OPMA 2015. "Helping the community tackle ice." Media release accessed online 17/08/15 at: www.pm.gov.au/media/2015-08-16/helping-community-tackle-ice

Quirion, B. 2003. "From rehabilitation to risk management: the goals of methadone programmes in Canada.” International Journal of Drug Policy 14 (3): 247-255.

Race, K. 2009. Pleasure consuming medicine: The queer politics of drugs. Durham \& London: Duke University Press.

Ritter, A. 2011. "The role of research evidence in drug policy development in Australia." Politicka misao 48 (5): 141-156.

Ritter, A. and Bammer, G. 2010. "Models of policy-making and their relevance for drug research." Drug and Alcohol Review 29 (4): 352-357.

Roe, G. 2005. "Harm reduction as paradigm: Is better than bad good enough? The origins of harm reduction." Critical Public Health 13 (3): 243-250. 
Seear, K. and Fraser, S. 2014. "The addict as victim: producing the 'problem' of addiction in Australian victims of crime compensation laws." International Journal of Drug Policy 25 (5): 826-835.

Stevens, A. and Ritter, A. 2013. "How can and do empirical studies influence drug policies? Narratives and complexity in the use of evidence in policy making." Drugs: Education, Prevention and Policy 20 (3): 169-174.

Strike, C., Myers, T. and Milson, M. 2004. "Finding a place for needle exchange programs." Critical Public Health 41 (3): 261-275.

Temenos, C. 2015. "Mobilizing drug policy activism: Conferences, convergence spaces and ephemeral fixtures in social movement mobilization." Space and Polity early online $11 / 08 / 15$

Warner, M. 2002. "Publics and Counterpublics." Public Culture 14 (1): 49-90.

Treloar, C. and Fraser, S. 2007. "Public opinion on needle and syringe programmes: Avoiding assumptions for policy and practice." Drug and Alcohol Review 26 (4): 355-361.

Walden, I. 2015. Talking back to policy: Aboriginal participation in policy making. (PhD unpublished thesis), UNSW Australia.

Wodak, A. 2008. "Going soft on evidence and due process: Canada adopts US style harm maximization.” International Journal of Drug Policy 19 (3): 226-228. 
Wynne, B. 2006. "Public engagement as a means of restoring public trust in science - Hitting the notes, but missing the music." Community Genetics 9 (3): 211-220.

${ }^{1}$ The expression 'alcohol and other drug' is the standard way of referring to drugs in Australian research and policy. It was devised as a means of drawing attention to the place of alcohol as a drug (historically it has not been seen as part of the category of 'drugs'), and to emphasize the primacy of alcohol in harms associated with drug use.

${ }^{2}$ It is beyond the scope of this article to consider these factors in depth, but it is worth noting as do Adams and Hess (2001: 16) that 'the political convergence around community may be seen as both a debate within neo-liberalism and as an alternative put forward by the opponents of liberalism'.

${ }^{3}$ For example, we previously noted that some academic literature is concerned with the extent to which policymakers take into account the voices and concerns of 'affected populations', and the extent to which policymaking processes are inclusive (e.g. Lancaster, Sutherland and Ritter, 2014; Lancaster, Ritter and Sutherland, 2013; Mathew-Simmons, Sunderland and Ritter, 2013; Kerr et al., 2006; Jürgens, 2005). In contrast to our approach, some of that literature assumes (and thus constructs) pre-existing (albeit 'bounded') policy publics that should be consulted as a part of the policymaking endeavor. 